\title{
AN INVESTIGATION OF THE EFFECTIVENESS OF THE FRAMING SYSTEMS IN STEEL STRUCTURES SUBJECTED TO BLAST LOADING
}

\author{
Amy COFFIELD, Hojjat ADELI \\ Department of Civil, Environmental, and Geodetic Engineering, The Ohio State University, \\ 470 Hitchcock Hall, 2070 Neil Avenue, Columbus, OH 43220 USA
}

Received 16 Oct 2014; accepted 06 Nov 2014

\begin{abstract}
The effectiveness of different framing systems for three seismically designed steel frame structures subjected to blast loading is investigated. The three faming systems considered are: a moment resisting frame (MRF), a concentrically braced frame (CBF) and an eccentrically braced frame (EBF). The blast loads are assumed to be unconfined, free air burst detonated $15 \mathrm{ft}(4.572 \mathrm{~m})$ from one of the center columns. The structures are modeled and analyzed using the Applied Element Method, which allows the structure to be evaluated during and through failure. Failure modes are investigated through a plastic hinge analysis and member failure comparison. Also, a global response analysis is observed through comparison of roof deflections and accelerations. A conclusion of this research is that braced frames provide a higher level of resistance to the blast loading scenario investigated in this research. Both the CBF and EBF had a smaller number of failed members and plastic hinges compared to the MRF. They also had smaller roof deflection and acceleration. The CBF yielded the fewest number of plastic hinges but the EBF had a slightly fewer number of failed members.
\end{abstract}

Keywords: steel frame, blast loading, moment resisting frame, concentrically braced frame.

\section{Introduction}

Over the last few decades, terrorist attacks and accidental explosions have brought on a need for research in the area of structural response subjected to blast loading conditions. An explosion within or surrounding a building can have disastrous effects causing not only structural damage or failure but also loss of human life. In order to prevent this kind of tragedy, research to help understand the blast phenomena and the response of a structure under blast loading conditions is essential. This will aid in the development of design methods and procedures to prevent structural failure in blast loading situations.

While nonlinear dynamic analysis of structures has a long history (Adeli et al. 1978) research on structural response under explosive loading is relatively recent. Most research in the area of structural blast analysis over the past few years has been limited to the local response of a steel or concrete structural member such as a column, beam or slab. Ngo et al. (2007) studied ground floor concrete columns subjected to blast loads and found that by increasing the strength of the concrete and decreasing the spacing of the shear reinforcements the column would make them more energy absorptive and, therefore, more effective for a blast loading situation. Yusof et al. (2010) investigated the behavior of steel fiber reinforced concrete panels (Finckh, Zilch 2012) with varying volumes of steel fibers and found that by increasing the volume of the steel fibers the panels became more blast resistant.
Lee et al. (2009) used the finite element method and computation fluid dynamics to study deep, wide flange columns often used in seismic design and found that they can be highly vulnerable under blast loads, especially in the weak axis direction. Ballantyne et al. (2010) also studied wide flange columns under blast loading conditions, in particular the blast wave and steel column interaction. They found that based on the shape of the column, the wave interacts and flows around the flanges such that the reflected blast pressures assumed in certain analysis procedures can be reduced by nearly $50 \%$ in some steel columns.

Little research has been reported on the response of an entire structure subjected to blast loading. Saleh and Adeli (1998) present optimal control of multistory building structures subjected to both internal blast loading at different floor levels and external blast loading from outside the structure. Luccioni et al. (2004) created a full numerical simulation of the Argentine Israelite Mutual Association (AMIA) reinforced concrete structure after the 1994 terrorist attack in Buenos Aires. It was concluded that the collapse was due to the destruction of several of the lower load carrying columns. Their research showed that numerical methods could accurately simulate the real life explosions. Some blast resistant research has also been conducted through the use of progressive collapse analysis methods, which assumes a "post-blast" situation in which one or more columns is removed under the assumption that it fails during the blast. Khandelwa 
et al. (2009) used progressive collapse analysis to study the collapse resistance of seismically designed steel braced frames. Two dimensional, ten-story and five-bay concentrically braced frames and eccentrically braced frames were analyzed using the alternate path method. They found that an eccentrically braced frame used in their research was less vulnerable to collapse than concentrically braced frames assuming the loss of a ground story column. A similar study by Kim et al. (2011) used progressive collapse methods to analyze eight different framing systems including moment resisting frames and various combinations of $\mathrm{X}, \mathrm{K}$ and $\mathrm{V}$ bracings. Each twodimensional model consisted of a four story steel frame with four bays and bracing in the center two bays. The center column was removed from each model. Progressive collapse analysis was performed and it was found that the best way to prevent collapse in braced structures would be to reinforce the columns connected to the braces.

The main limitation of using progressive collapse analysis method for blast loading is that it neglects the dynamic effects from the blast itself. Lee et al. (2011) evaluated a three story moment resisting steel frame structure subjected to initial dynamic blast effects and then performed a progressive collapse study of the structure assuming the loss of the column closest to the blast. They found that the strain rate effects from the initial blast deformation need to be taken into account prior to the progressive collapse analysis for it to accurately model the structural response.

This paper examines the structural response of three dimensional steel frame structures subjected to blast loading for three different framing systems: a moment resisting frame (MRF), a concentrically braced frame (CBF) and an eccentrically braced frame (EBF).The framing systems are evaluated using the Applied Element Method (AEM). A comparative study is performed to determine the effectiveness of different seismic resisting systems.

\section{Applied Element Method}

The Applied Element Method (AEM) was first presented by Meguro and Tagel-Din (2000) and has the unique advantage of being able to model structural behavior from initial loading to member failure to complete structural collapse. Like the finite element method (FEM), structures are modeled as an assembly of distinct elements in some sort of mesh assembly that together represent a large structure. However, unlike the FEM, elements in the AEM are considered rigid bodies and instead of being connected at a single node point, the elements in the AEM are connected along the element surfaces by a set of springs. Elements are assumed to be connected by one normal and two shear springs at each connection point between the two given elements. Each group of springs at a connection point completely represents the stresses and deformations of a certain volume of the two elements. Figure 1 presents two typical elements and the normal and shear springs between them. Figure 2 shows the area of influence of a typical set of springs.

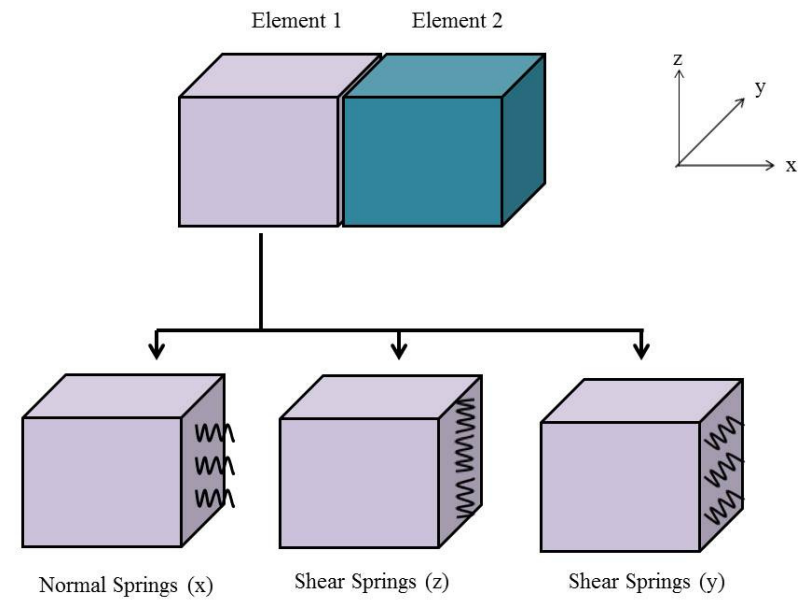

Fig. 1. AEM elements and springs

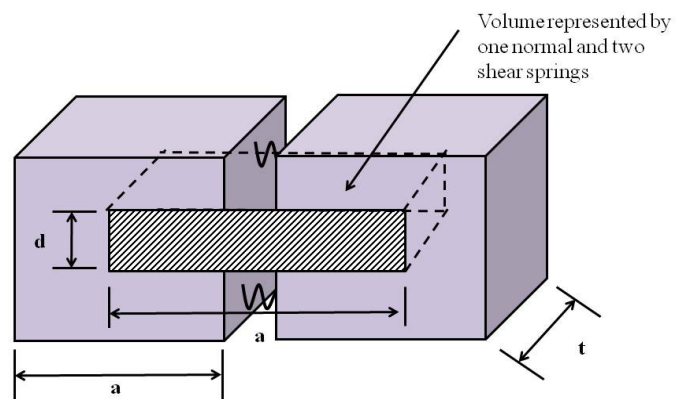

Fig. 2. Connection of two elements in the AEM approach

In the AEM approach each element is represented as a rigid body meaning that the shape of the individual element will not change. The element deformations are represented in the three aforementioned spring stiffnesses connecting elements to each other and therefore are concentrated at the element face. Since the elements are connected along the element faces as opposed to a single node, the elements have the ability to separate if the average stress at the connection point reaches the materials ultimate stress. This gives the AEM a unique advantage over the FEM because it allows for the analysis of structural failure and collapse.

The method works by first finding the stiffness of each individual spring between two given elements. This is determined by the modulus of elasticity of the material, the length of the spring taken as the center to center point of each element, and the thickness of the element. The equation for the stiffness of the spring in the normal direction is given by:

$$
K_{n}=\frac{E d t}{a},
$$

where: $E$ is the modulus of elasticity, $t$ is the thickness of the element as determined by the mesh size, $d$ is the distance between springs, and $a$ is the length of the representative area as seen in Figure 2. The equation for the stiffness of a tangential/shear spring is given by:

$$
K_{S}=\frac{G d t}{a},
$$

where $G$ is the shear modulus of the material. 
Once the stiffness of the connection springs are known a spring stiffness matrix that combines the normal and shear springs is created based on the spring stiffness and orientation. Like the FEM, the individual stiffness matrices are then summed into a global stiffness matrix:

$$
K_{G} \Delta=F,
$$

where $\boldsymbol{K}_{\boldsymbol{G}}$ is the global stiffness matrix, $\Delta$ is the spring displacement vector and $\boldsymbol{F}$ is the load vector. The load vector is found based on the forces applied to each element. The system is then solved and the deformation and the stress and strain at each connection point along each element face are obtained. The structural stiffness for each element is found through the spring stiffness of the representative area of each element to element connection.

Although the AEM is a relatively new method, previous and recent research by Myorca and Meguro (2004), Sasani (2008), and Lupoae and Bucur (2009) have all shown good correlation between numeric simulations using AEM and experimental results. Myorca and Meguro (2004) validated the AEM while studying the response of unreinforced masonry walls before and after being retrofitted with polypropylene bands. The study compared the response of eight different masonry walls under vertical and horizontal loads experimentally. They found that there was good agreement in the force deformation and crack pattern between the experimental results and the numerical model using AEM. Sasani (2008) evaluated the response of Hotel San Diego following the removal of two exterior columns. Strain gages were used to measure the strain of the beams and columns and potentiometers were used to measure the global and local deformations. The results from the measurement devices on the sixstory reinforced concrete hotel during certain column removal showed good agreement between the experimental results and the results found using the AEM. Lupoae and Bucur (2009) modeled a six-story rectangular reinforced concrete building with load-bearing walls and columns. The structure was demolished by strategically placed explosive charges that caused a completely downward collapse of the building. The structure was then modeled with the AEM and a corresponding demolition scenario was created. The mode of stress redistribution, loads redistribution and axial forces in the columns above the removed columns were all examined. The results showed good correlation between the numerical simulation using AEM and the actual demolition of the structure.

\section{Blast loading}

When determining blast loads on a structure, it is essential to first understand the explosion and the blast phenomena itself. A blast can be defined as a sudden and violent release of energy. There are several categories of explosives based upon the chemical and physical properties of the bomb. However, in all cases there is a very hot, dense, high-pressure gas that is released at time of detonation. A pressure front is created by the high pressure gas that propagates into the atmosphere causing the blast wave. The pressure front decreases with distance from the blast source. The most important characteristics of the blast wave is the almost instantaneous rise in ambient pressure to the much higher pressure known as the peak overpressure, $P_{s o^{+}}$(UFC 2008). At a given distance, the peak overpressure decays with time until it reduces back to the original ambient pressure. This portion of the blast wave is referred to as the positive phase of the wave and the time of the positive phase is referred to as the positive blast duration, $t_{d+}$. In most cases, the pressure will then continue to decay creating a partial vacuum until it eventually rises back to the ambient pressure. This is referred to as the negative phase of the pressure wave and lasts for a duration referred to as the negative phase duration, $t_{d-\text {. }}$. The minimum pressure during the negative phase is known as the peak underpressure, $P_{s o .}$. The entire process happens very rapidly and in most cases lasts less than a tenth of a second (UFC 2008). A sample pressure-time profile is shown in Figure 3. Other important parameters of the blast pressure profiles are the positive and negative impulses, which are defined as the area under the positive and negative pressure time profile curve, respectively. They are often used when creating simplified models of the blast pressure profiles.

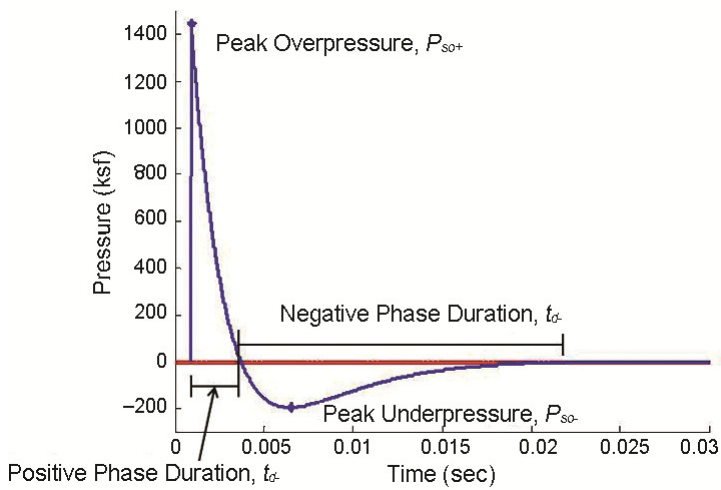

Fig. 3. Example pressure-time profile $(1 \mathrm{ksf}=48 \mathrm{kPa})$

There are two main parameters that determine the impact or the threat of a conventional explosive. First, there is the magnitude of the explosion which is referred to as the bomb size or charge weight, $W$. This is determined by the chemical and physical properties of the explosive. In practice, the charge weight is usually given as an equivalent mass of TNT. The second parameter is the standoff distance, $R$, which is the distance between the blast source and the point of interest or the target. From these two parameters, almost all characteristics of the blast wave can be found. In practice, a scaled distance factor, $Z$, based on the charge weight and the standoff distance (usually in meters) is typically used when determining certain blast wave characteristics, such as peak overpressure, phase duration and impulse. The following equation is often used to find the scaled distance factor $Z$ (UFC 2008):

$$
Z=\frac{R}{w^{1 / 3}}
$$


The two main categories of explosions are confined and unconfined explosions (UFC 2008). A confined explosion means that the explosion happens within an enclosed space, whereas an unconfined explosion happens in an open environment. An unconfined explosion can be categorized further into: a) free air burst meaning that the blast occurs such that no amplification of the initial shock wave occurs; b) air burst meaning that the blast is located at a distance from and above the structure such that the ground reflections of the initial wave occur prior to the arrival of the blast wave to the structure. Like sound and light waves, shock waves can be reflected and since they can travel faster than the speed of sound when they hit the ground surface a "Mach" front is created based on the mach number of the shock wave; and c) a surface burst meaning that the blast occurs close to or on the ground such that the wave is reflected by the ground at the time of detonation. This occurs when the charge height is less than half of the charge radius, which is defined as the distance from the blast source to the near point of the structure.

When the blast waves reach the front surface of the structure or any object perpendicular to the blast wave, a reflection of the blast waves occurs, which causes an amplification of the peak overpressure. The amplified pressure is known as the reflected pressure, $P_{r}$. The reflected pressure is a function of the peak overpressure, the ambient pressure, and the angle of the wave (UFC 2008). The reflected pressure is ignored in this research.

Blast parameters, such as the peak overpressure, $P_{s o}$, peak reflected pressure, positive impulse, $i_{s}+$, reflected impulse, $i_{s^{-}}$, arrival time, $t_{a}$, the blast duration, $t_{d}$, the shock velocity, $U$ and the positive wave length, $L_{w}$ have been found through experimentally-obtained data for each category of blast. Presented in Figure 4 are the blast parameters for an unconfined, free-air burst (UFC 2008). This research uses the values given in Figure 4 to find the peak overpressure, the positive impulse, the arrival time and the blast duration. These factors all vary with the scaled distance factor, $Z$.

Blast pressure-time profiles for a given location can also be determined through exponential decay formula (Friedlander 1947):

$$
P=P_{s o} \mathrm{e}^{t / t d} \cdot\left(1-\left(\mathrm{t} / \mathrm{t}_{d}\right)\right)
$$

In this research, a linear approximation of the blast pressure time profile is used and will be discussed in a subsequent section.

\section{Modelling}

\subsection{Building design}

Three 10-story, 5-bay steel structures designed according to AISC (LRFD) (AISC 2010) and ASCE 7-10 (ASCE 2010) are considered in this research: one moment-resisting frame (MRF), one concentrically braced frame (CBF), and one eccentrically braced frame (EBF). They are designed based on a uniform live load of $50 \mathrm{psf}\left(2.394 \mathrm{kN} / \mathrm{m}^{2}\right)$ and a uniform dead load consisting of the self-weight of the structure and an additional $15 \mathrm{psf}\left(1.197 \mathrm{kN} / \mathrm{m}^{2}\right)$ to account

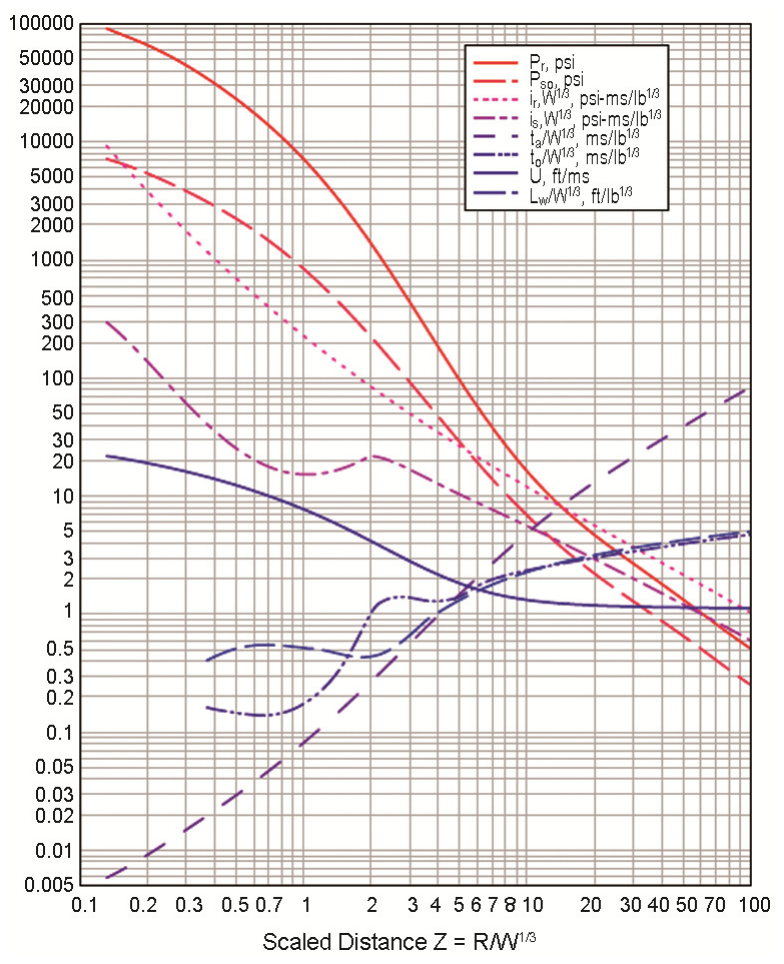

Fig. 4. Positive phase shock wave parameters for explosion in free air at sea level (UFC 2008)

for partitions, ceilings, and other additional structural items. A 9-in $(229 \mathrm{~mm})$ concrete slab is assumed at every floor. An additional dead load of $250 \mathrm{plf}(3.65 \mathrm{kN} / \mathrm{m})$ was added to exterior beams to account for cladding. A category B seismic load is assumed and an $85 \mathrm{mph}$ $(137 \mathrm{~km} / \mathrm{h})$ wind load at exposure category $\mathrm{C}$ with a gust and directionality wind factor of 0.85 . Beams and columns are selected from the AISC Steel Construction Manual database using wide flange (W) shapes with a yield stress of $50 \mathrm{ksi}(345 \mathrm{MPa})$ and an ultimate strength of $65 \mathrm{ksi}(450 \mathrm{MPa})$. All structures have the same uniform story height of $10 \mathrm{ft}(3 \mathrm{~m})$, except for the first story which has a story height of $12 \mathrm{ft}(3.7 \mathrm{~m})$ and a uniform bay spacing of $25 \mathrm{ft}(7.6 \mathrm{~m})$. The EBF has a bracing eccentricity of $5 \mathrm{ft}(1.5 \mathrm{~m})$ on center. Figures 5 (a) to $5(\mathrm{c})$ present three dimensional perspective views of the regular MRF, CBF and EBF structures, respectively. A 4-in. $(102 \mathrm{~mm})$ thick brick curtain wall is added to the structural face closest to the blast. The brick wall is attached to the structural frame at the columns and is used during analysis to help properly distribute the blast loads.

Designs for the MRF, EBF and CBF structures were obtained from previous research that utilized ETABS as the design software (Young, Adeli 2013, 2014). However, the previously designed MRF had a uniform bay spacing of $15 \mathrm{ft}(4.6 \mathrm{~m})$ and therefore could not be compared to the EBF and CBF models. The MRF was then redesigned in this research utilizing STAAD Pro V8 $i$ as the design software. Member data (all W shapes) for the three structures are given in Tables 1 to 3. The material properties used in this research for the steel, concrete, and brick are given in Table 4. All columns are assumed to be in a fixed condition at the ground level with the footing material being normal concrete. 


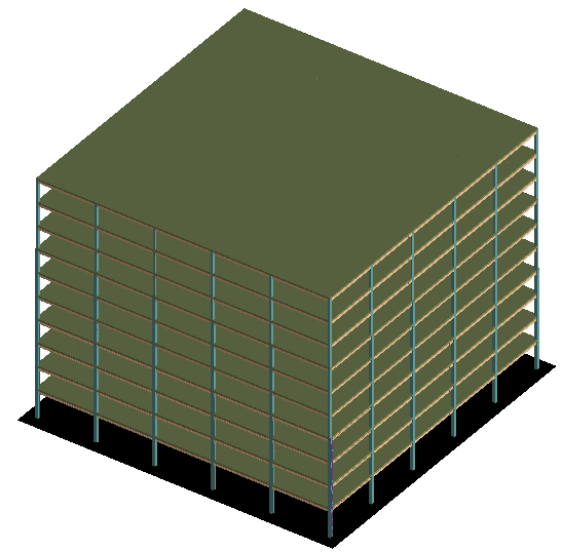

(a) MRF

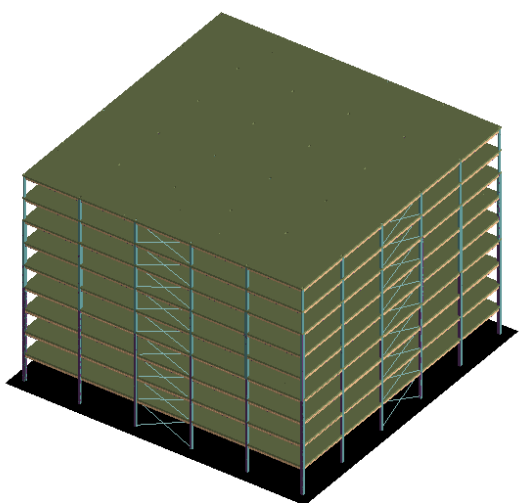

(b) $\mathrm{CBF}$

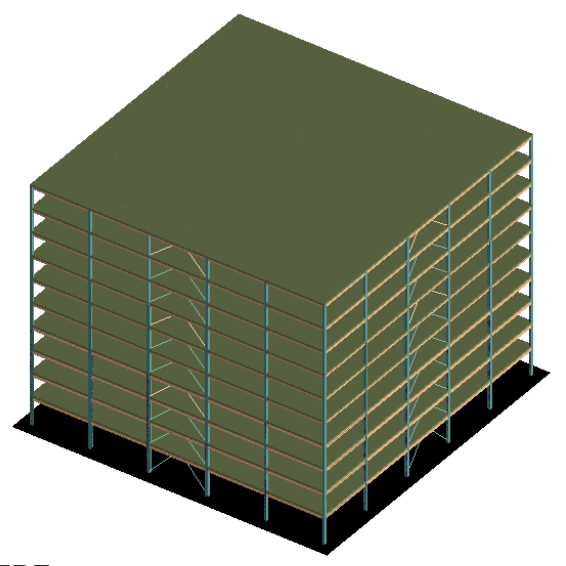

(c) $\mathrm{EBF}$

Fig. 5. Three-dimensional building structures studied in this research

Table 1. Member designs for Moment Resisting Frame (MRF)

\begin{tabular}{|c|c|c|c|}
\hline $\begin{array}{l}\text { Story } \\
\text { (i) }\end{array}$ & $\begin{array}{l}\text { Column } \\
\text { Section }\end{array}$ & $\begin{array}{l}\text { Beam Section - } \\
\text { Interior }\end{array}$ & $\begin{array}{c}\text { Beam Section - } \\
\text { Perimeter }\end{array}$ \\
\hline 10 & $\mathrm{~W} 14 \times 61$ & $\mathrm{~W} 14 \times 68$ & $\mathrm{~W} 14 \times 48$ \\
\hline 9 & $\mathrm{~W} 14 \times 61$ & $\mathrm{~W} 14 \times 68$ & $\mathrm{~W} 14 \times 48$ \\
\hline 8 & $\mathrm{~W} 14 \times 61$ & W14×68 & $\mathrm{W} 14 \times 48$ \\
\hline 7 & $\mathrm{~W} 14 \times 99$ & $\mathrm{~W} 14 \times 48$ & $\mathrm{~W} 14 \times 48$ \\
\hline 6 & $\mathrm{~W} 14 \times 99$ & $\mathrm{~W} 14 \times 48$ & $\mathrm{~W} 14 \times 48$ \\
\hline 5 & $\mathrm{~W} 14 \times 99$ & $\mathrm{~W} 14 \times 48$ & $\mathrm{~W} 14 \times 48$ \\
\hline 4 & $\mathrm{~W} 14 \times 193$ & W16 $\times 57$ & $\mathrm{~W} 16 \times 45$ \\
\hline 3 & $\mathrm{~W} 14 \times 193$ & W16 $\times 57$ & W16 $\times 45$ \\
\hline 2 & $\mathrm{~W} 14 \times 193$ & W16 167 & $\mathrm{~W} 16 \times 45$ \\
\hline 1 & $\mathrm{~W} 14 \times 193$ & W16×57 & $\mathrm{W} 16 \times 45$ \\
\hline
\end{tabular}

Table 2. Member designs for Concentrically Braced Frame (CBF)

\begin{tabular}{|c|c|c|c|c|}
\hline $\begin{array}{l}\text { Story } \\
\text { (i) }\end{array}$ & $\begin{array}{l}\text { Column } \\
\text { Section }\end{array}$ & $\begin{array}{l}\text { Beam - } \\
\text { Interior }\end{array}$ & $\begin{array}{c}\text { Beam - } \\
\text { Perimeter }\end{array}$ & $\begin{array}{l}\text { Bracing } \\
\text { Section }\end{array}$ \\
\hline 10 & $\mathrm{~W} 14 \times 53$ & $\mathrm{~W} 14 \times 48$ & $\mathrm{~W} 14 \times 38$ & W14×68 \\
\hline 9 & $\mathrm{~W} 14 \times 53$ & $\mathrm{~W} 14 \times 48$ & W14×38 & W14×68 \\
\hline 8 & $\mathrm{~W} 14 \times 53$ & $\mathrm{~W} 14 \times 48$ & $\mathrm{~W} 14 \times 38$ & W14×68 \\
\hline 7 & W18×97 & $\mathrm{W} 14 \times 43$ & $\mathrm{~W} 14 \times 34$ & W14×68 \\
\hline 6 & $\mathrm{~W} 18 \times 97$ & $\mathrm{~W} 14 \times 43$ & $\mathrm{~W} 14 \times 34$ & W14×68 \\
\hline 5 & $\mathrm{~W} 18 \times 97$ & $\mathrm{~W} 14 \times 43$ & $\mathrm{~W} 14 \times 34$ & W14×68 \\
\hline 4 & $\mathrm{~W} 12 \times 190$ & $\mathrm{~W} 14 \times 43$ & $\mathrm{~W} 14 \times 34$ & $\mathrm{~W} 12 \times 96$ \\
\hline 3 & $\mathrm{~W} 12 \times 190$ & $\mathrm{~W} 14 \times 43$ & $\mathrm{~W} 14 \times 34$ & $\mathrm{~W} 12 \times 96$ \\
\hline 2 & $\mathrm{~W} 12 \times 190$ & $\mathrm{~W} 14 \times 43$ & $\mathrm{~W} 14 \times 34$ & $\mathrm{~W} 12 \times 96$ \\
\hline 1 & $\mathrm{~W} 12 \times 190$ & $\mathrm{~W} 14 \times 43$ & $\mathrm{~W} 14 \times 34$ & $\mathrm{~W} 12 \times 96$ \\
\hline
\end{tabular}

Table 3. Member designs for Eccentrically Braced Frame (EBF)

\begin{tabular}{c|c|c|c|c}
\hline $\begin{array}{c}\text { Story } \\
\text { (i) }\end{array}$ & $\begin{array}{c}\text { Column } \\
\text { Section }\end{array}$ & $\begin{array}{c}\text { Beam }- \\
\text { Interior }\end{array}$ & $\begin{array}{c}\text { Beam }- \\
\text { Perimeter }\end{array}$ & $\begin{array}{c}\text { Bracing } \\
\text { Section }\end{array}$ \\
\hline 10 & $\mathrm{~W} 14 \times 68$ & $\mathrm{~W} 14 \times 48$ & $\mathrm{~W} 14 \times 38$ & $\mathrm{~W} 12 \times 30$ \\
\hline 9 & $\mathrm{~W} 14 \times 68$ & $\mathrm{~W} 14 \times 48$ & $\mathrm{~W} 14 \times 38$ & $\mathrm{~W} 12 \times 30$ \\
\hline 8 & $\mathrm{~W} 14 \times 68$ & $\mathrm{~W} 14 \times 48$ & $\mathrm{~W} 14 \times 38$ & $\mathrm{~W} 12 \times 30$ \\
\hline 7 & $\mathrm{~W} 12 \times 96$ & $\mathrm{~W} 14 \times 43$ & $\mathrm{~W} 12 \times 45$ & $\mathrm{~W} 12 \times 30$ \\
\hline 6 & $\mathrm{~W} 12 \times 96$ & $\mathrm{~W} 14 \times 43$ & $\mathrm{~W} 12 \times 45$ & $\mathrm{~W} 12 \times 30$ \\
\hline 5 & $\mathrm{~W} 12 \times 96$ & $\mathrm{~W} 14 \times 43$ & $\mathrm{~W} 12 \times 45$ & $\mathrm{~W} 12 \times 30$ \\
\hline 4 & $\mathrm{~W} 12 \times 152$ & $\mathrm{~W} 14 \times 43$ & $\mathrm{~W} 16 \times 77$ & $\mathrm{~W} 12 \times 50$ \\
\hline 3 & $\mathrm{~W} 12 \times 152$ & $\mathrm{~W} 14 \times 43$ & $\mathrm{~W} 16 \times 77$ & $\mathrm{~W} 12 \times 50$ \\
\hline 2 & $\mathrm{~W} 12 \times 152$ & $\mathrm{~W} 14 \times 43$ & $\mathrm{~W} 16 \times 77$ & $\mathrm{~W} 12 \times 50$ \\
\hline 1 & $\mathrm{~W} 12 \times 152$ & $\mathrm{~W} 14 \times 43$ & $\mathrm{~W} 16 \times 77$ & $\mathrm{~W} 12 \times 50$ \\
\hline
\end{tabular}

Table 4. Material properties $(1 \mathrm{ksi}=6.9 \mathrm{MPa}$, $1 \mathrm{kcf}=0.0064 \mathrm{kN} / \mathrm{m}^{3}$ )

\begin{tabular}{c|c|c|c|c|c}
\hline Steel & $\begin{array}{c}\text { Young's } \\
\text { Modulus } \\
(\mathrm{ksi})\end{array}$ & $\begin{array}{c}\text { Shear } \\
\text { Modulus } \\
(\mathrm{ksi})\end{array}$ & $\begin{array}{c}\text { Yield } \\
\text { Strength } \\
(\mathrm{ksi})\end{array}$ & $\begin{array}{c}\text { Ultimate } \\
\text { Strength } \\
(\mathrm{ksi})\end{array}$ & $\begin{array}{c}\text { Specific } \\
\text { Weight } \\
(\mathrm{kcf})\end{array}$ \\
\hline $\begin{array}{c}\text { Young's } \\
\text { Modulus } \\
\text { (ksi) }\end{array}$ & $\begin{array}{c}\text { Modulus } \\
\text { (ksi) }\end{array}$ & $\begin{array}{c}\text { Thensile } \\
\text { Strength } \\
\text { (ksi) }\end{array}$ & $\begin{array}{c}\text { Com- } \\
\text { pressive } \\
\text { Strength } \\
\text { (ksi) }\end{array}$ & $\begin{array}{c}\text { Specific } \\
\text { Weight } \\
\text { (kcf) }\end{array}$ \\
\hline $\begin{array}{c}\text { Con } \\
\text { crete }\end{array}$ & 3800 & 1520 & 0.4 & 65 & 0.489 \\
\hline $\begin{array}{c}\text { Young's } \\
\text { Modulus } \\
\text { (ksi) }\end{array}$ & $\begin{array}{c}\text { Shear } \\
\text { Modulus }\end{array}$ & $\begin{array}{c}\text { Tensile } \\
\text { Strengt } \\
\text { h (ksi) }\end{array}$ & $\begin{array}{c}\text { Com- } \\
\text { pressive } \\
\text { Strengt } \\
\text { h (ksi) }\end{array}$ & $\begin{array}{c}\text { Wpecific } \\
\text { Weight } \\
\text { (kcf) }\end{array}$ \\
\hline 2844 & 1137 & 0.14 & 1.5 & 0.156 \\
\hline
\end{tabular}




\subsection{Applying the AEM}

Three dimensional cuboid elements are used in this research. This is done by applying three springs per element face, totaling 18 springs per element for a fully surrounded element. A bi-linear constitutive curve shown in Figure 6 is used to model the inelastic behavior of steel and post-yield stress. Dynamic mechanical properties of the materials, such as strain hardening effects, are not considered in this research.

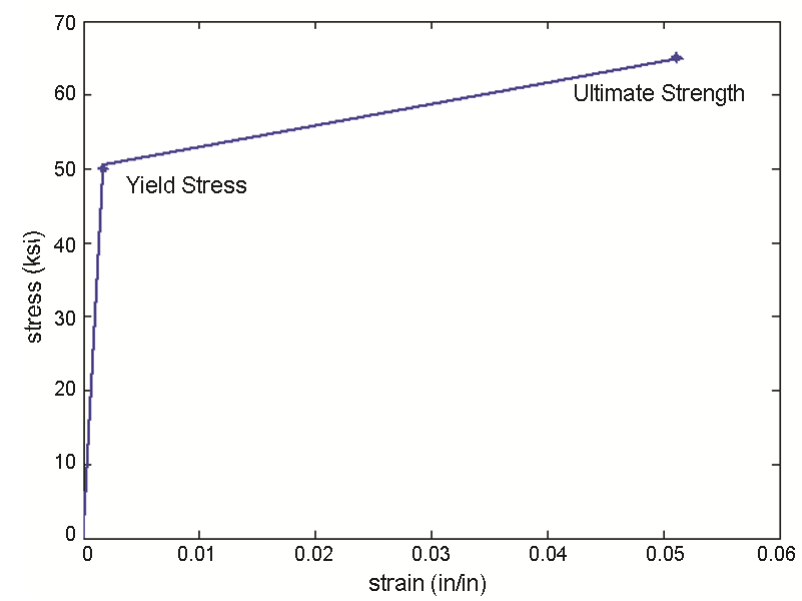

Fig. 6. Idealized stress and strain curve for steel $(1 \mathrm{ksi}=6.9 \mathrm{MPa}, 1 \mathrm{in}=25.4 \mathrm{~m})$

Like the finite element method, an important issue when using AEM is to create an appropriate mesh. This determines the distance parameters used in finding the spring/structural stiffness discussed in the previous section. For each beam, column, slab, or wall a mesh size is carefully selected based on proximity to the blast source. Members closest to the blast require more elements. After trying various mesh sizes, the following scheme was used. The beams and columns in the first four stories and the two bays closest to the blast have a mesh size of $15 \times 3 \times 3$ for a total of 135 elements per structural member. All other beams have a mesh size of $10 \times 1 \times 1$ for a total of 10 elements per beam. All other columns have a mesh size of $8 \times 1 \times 1$ for a total of 8 elements per column. The mesh for a typical beam with 10 elements is shown in Figure 7. The 9-inch slab on each floor is placed on top of the beams and is considered to be continuous in both

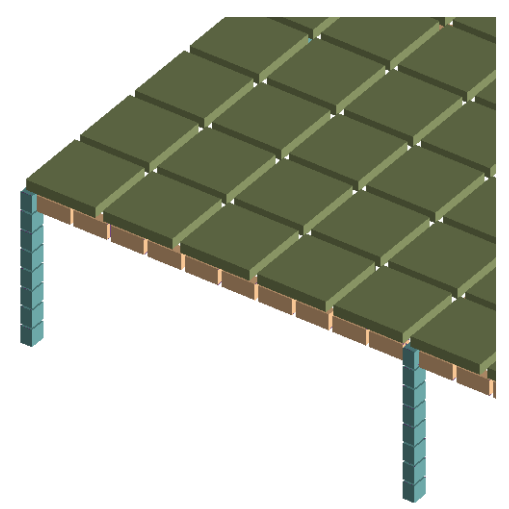

Fig. 7. Sample beam, column and floor slab mesh (Floor 10) horizontal directions. The mesh size for the slab in the first four stories is $50 \times 50 \times 1$ with a total of 2500 elements per slab. The top six floors have a mesh size of $25 \times 25 \times 1$ for a total of 625 elements per slab. Finally, a 4-inch $(102 \mathrm{~mm})$ brick curtain wall is used on the outside face closest to the blast with a mesh size of $65 \times 10 \times 1$ on the first four stories and $45 \times 6 \times 1$ on the rest for a total of 650 and 270 elements per wall, respectively. The braces in the $\mathrm{CBF}$ and the EBF are modeled as one element each. There are approximately 40,000 elements in each 3D structure.

The interactions between the elements are as described in the AEM section. The collision of already separated elements is considered through the use of contact springs. If two separated elements come into contact with each other, the interaction between them can be found using three contact springs at every contact point. This allows for automatic analysis of fragmentation due to the blast loads.

\subsection{Applying the blast loads}

For this research, all blasts are assumed to be unconfined, free air burst. Following this assumption, blast parameter data used in this research, such as the peak overpressure, $P_{s o}$, positive impulse, $i_{s}+$, arrival time, $t_{a}$, and the blast duration, $t_{d}$ are found based on experimentally obtained data presented in Figure 4 (UFC 2008). These factors all vary with the scaled distance factor, $Z$.

The pressure-time profiles for a given location have been simplified using a linear approximation. This is done by finding an equivalent impulse triangle that matches the impulse provided in Figure 4 and using the same peak overpressure. An example simplified pressure-time profile is shown in Figure 8. No reflected pressure, side or roof overpressure, or negative blast pressure is considered.

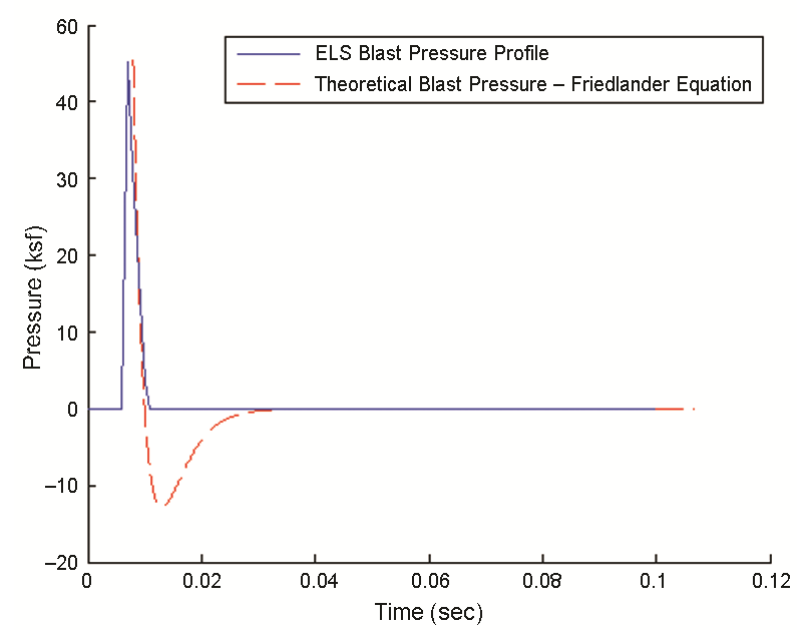

Fig. 8. Sample blast pressure-time profile: linear approximation vs. theoretical profile $(1 \mathrm{ksf}=48 \mathrm{kPa})$

Blast pressures are applied only to elements in the direct line of sight to the blast source. The elements are loaded when the blast wave reaches the element. An equivalent force is found by taking the pressure value at 
that time and multiplying it by the element surface area. The blast loads are assumed to be perpendicular to the element in all cases. The blast loads applied to the brick elements are then transmitted through the cladding system to the structure through the use of the connection springs as described in the AEM section. At the wall closer to the blast, where the wall breaks apart, the loads are transmitted to the structure through the fragmented brick elements.

In this research, all blast locations are assumed to be positioned $5 \mathrm{ft}(4.6 \mathrm{~m})$ above the ground and $15 \mathrm{ft}(4.6 \mathrm{~m})$ from the far center column. The blast is assumed to be caused by a spherical TNT bomb with two different weights $(w)$ of 2 kips $(8.9 \mathrm{kN})$ and 4 kips $(17.8 \mathrm{kN})$. To put this in prospective, the blast weight of the 1995 Oklahoma City bombing was roughly 4 kips $(8.9 \mathrm{kN})$ with a stand-off distance of about $15 \mathrm{ft}(4.6 \mathrm{~m})$. Figure 9 shows the location of the blast source which is typical for all models in this research. Table 5 gives the peak blast pressure $\left(P_{s o}\right)$, arrival time $\left(t_{a}\right)$ and positive phase duration $\left(t_{d}\right)$ for the nearest and farthest points reached by the blast wave for each structure.

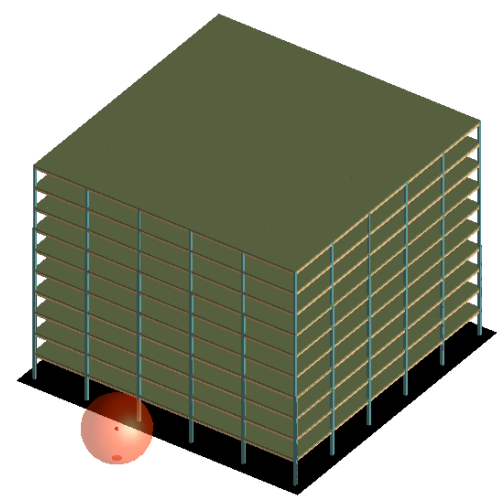

Fig. 9. Location of blast source - typical for all structures

Due to the nearly instantaneous nature of the blast pressure-time reaction, a very small analysis time step is required to ensure that the structure is loaded by the correct blast pressure-time distribution. The analysis time step from the time of detonation to the blast wave leaving the structure is 0.0001 seconds. After the blast wave is applied which is about $0.14-0.15$ seconds, the analysis continues for another 1.5 seconds at a time step of 0.001 seconds. This is done to study the post-blast behavior of the structure. Approximately 3,000 time steps are used for each model. The analysis is not continued more than 1.5 seconds because of the limitation of the available computing power. The analysis time for each model is in the order of 12-15 hours on an Intel Xeon CPU 5140 at $2.33 \mathrm{GHz}$ on a 64-bit Windows 7 Enterprise operating system with 2 GB RAM.

\section{Results}

The 10-story 5-bay MRF, CBF and EBF structures subjected to two different magnitudes of blast loads, 2 kips $(8.9 \mathrm{kN})$ and 4 kips $(17.8 \mathrm{kN})$, are analyzed using the AEM approach. For the given blast location and weights, all the structures undergo damage and member failure but none experience a total or partial collapse. As expected, the structural elements closest to the blast sustained the most damage due to the higher blast pressures. A plastic hinge analysis of each structure is performed (Adeli, Chyou 1986, 1987; Adeli, Mabrouk 1986; Park, Adeli 1995). Plastic hinges are found by examining the stress contours of each structural member. The points along each beam or column where the stress in the entire cross section of the member approaches the yield stress of steel are identified as plastic hinges. A member is considered failed whenever: a) three plastic hinges form in the member or b) two elements in the mesh are separated. Global response is compared through time-histories of the roof deflection and acceleration.

Table 6 provides a summary of plastic hinge formations and member failure information for the three structures subjected to $2-\mathrm{K}(8.9 \mathrm{kN})$ and $4-\mathrm{K}(17.8 \mathrm{kN})$ blast loads. All structures faced significant damage during the blast with either 5 or 6 failed members given the 2-K $(8.9 \mathrm{kN})$ blast load or 7 to 9 failed members given the $4-\mathrm{K}(17.8 \mathrm{kN})$ blast load. In all examples, plastic hinges begin to form almost instantaneously with the first forming in the column closest to the blast 0.003 and 0.002 seconds after detonation for the $2-\mathrm{K}(8.9 \mathrm{kN})$ and $4-\mathrm{K}(17.8 \mathrm{kN})$ blast, respectively. They continue to form as the blast wave spreads throughout the structure. Figures 10 and 11 show the plastic hinge locations as well as the failed members as indicated by a thick line for the three structures subjected to the $2-\mathrm{K}(8.9 \mathrm{kN})$ and $4-\mathrm{K}$ $(17.8 \mathrm{kN})$ blast load, respectively. The plastic hinges

Table 5. Specific blast parameters for the near and far point for MRF, CBF and EBF $(1 \mathrm{kips}=4.45 \mathrm{kN}, 1 \mathrm{ft}=0.31 \mathrm{~m}, 1 \mathrm{ksf}=48 \mathrm{kPa})$

\begin{tabular}{|c|c|c|c|c|c|c|c|c|c|}
\hline \multirow{2}{*}{$\begin{array}{l}\text { Blast Weight } \\
\text { (Kips) }\end{array}$} & \multirow{2}{*}{$\begin{array}{l}\text { Structure } \\
\text { (kips) }\end{array}$} & \multicolumn{2}{|c|}{$\begin{array}{l}\text { Distance } \\
\text { (ft) }\end{array}$} & \multicolumn{2}{|c|}{$\begin{array}{l}\mathrm{P}_{\mathrm{so}^{+}} \\
(\mathrm{ksf})\end{array}$} & \multicolumn{2}{|c|}{$\begin{array}{c}\mathrm{t}_{\mathrm{a}} \\
(\mathrm{sec})\end{array}$} & \multicolumn{2}{|c|}{$\begin{array}{c}\mathrm{t}_{\mathrm{d}+} \\
(\mathrm{sec})\end{array}$} \\
\hline & & Near & Far & Near & Far & Near & Far & Near & Far \\
\hline \multirow{3}{*}{2} & MRF & 14.03 & 187.1 & 1457 & 1.68 & 0.0009 & 0.0951 & 0.0028 & 0.0412 \\
\hline & $\mathrm{CBF}$ & 14.23 & 187.26 & 1420 & 1.68 & 0.0009 & 0.0952 & 0.0028 & 0.0412 \\
\hline & EBF & 14.11 & 187.11 & 1442 & 1.68 & 0.0009 & 0.0951 & 0.0028 & 0.0412 \\
\hline \multirow{3}{*}{4} & MRF & 14.03 & 187.1 & 2194 & 2.9 & 0.0009 & 0.0839 & 0.0028 & 0.0472 \\
\hline & $\mathrm{CBF}$ & 14.23 & 187.26 & 2180 & 2.9 & 0.0009 & 0.083 & 0.0028 & 0.0472 \\
\hline & EBF & 14.11 & 187.11 & 2172 & 2.9 & 0.0009 & 0.0829 & 0.0028 & 0.0472 \\
\hline
\end{tabular}


Table 6. Plastic hinge and member failure for MRF, CBF and EBF $(1 \mathrm{kip}=4.49 \mathrm{kN})$

\begin{tabular}{|c|c|c|c|c|c|c|c|c|c|c|c|c|c|c|}
\hline \multirow{2}{*}{ 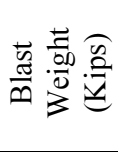 } & \multirow{2}{*}{$\underset{\mathscr{D}}{\stackrel{0}{0}}$} & \multicolumn{2}{|c|}{ Member Failure } & \multicolumn{11}{|c|}{ Number of Plastic Hinges } \\
\hline & & $\begin{array}{l}\text { Col- } \\
\text { umn }\end{array}$ & Beam & $\begin{array}{c}\text { Story } \\
1\end{array}$ & $\begin{array}{c}\text { Story } \\
2\end{array}$ & $\begin{array}{c}\text { Story } \\
3\end{array}$ & $\begin{array}{c}\text { Story } \\
4\end{array}$ & $\begin{array}{c}\text { Story } \\
5\end{array}$ & $\begin{array}{c}\text { Story } \\
6\end{array}$ & $\begin{array}{c}\text { Story } \\
7\end{array}$ & $\begin{array}{c}\text { Story } \\
8\end{array}$ & $\begin{array}{c}\text { Story } \\
9\end{array}$ & $\begin{array}{c}\text { Story } \\
10\end{array}$ & TOTAL \\
\hline \multirow{3}{*}{2} & MRF & 1 & 5 & 18 & 10 & 7 & 4 & 0 & 0 & 0 & 0 & 0 & 0 & 39 \\
\hline & $\mathrm{CBF}$ & 1 & 5 & 15 & 9 & 6 & 2 & 0 & 0 & 0 & 0 & 0 & 0 & 32 \\
\hline & EBF & 1 & 4 & 17 & 11 & 4 & 2 & 0 & 0 & 0 & 0 & 0 & 0 & 34 \\
\hline \multirow{3}{*}{4} & MRF & 1 & 8 & 19 & 13 & 13 & 8 & 0 & 0 & 0 & 0 & 0 & 0 & 53 \\
\hline & $\mathrm{CBF}$ & 1 & 7 & 17 & 12 & 9 & 7 & 0 & 0 & 0 & 0 & 0 & 0 & 45 \\
\hline & $\mathrm{EBF}$ & 1 & 6 & 17 & 13 & 11 & 8 & 0 & 0 & 0 & 0 & 0 & 0 & 49 \\
\hline
\end{tabular}

were formed in the first through fourth story beams and columns closest to the blast. They formed very quickly with approximately two-thirds (54-69\%) of them forming within 0.01 second of detonation in all examples. The maximum roof deflection and acceleration in the direction of the blast for each example is given in Table 7.

Table 7. Maximum roof deflection and acceleration for MRF, $\mathrm{CBF}$ and $\mathrm{EBF}(1 \mathrm{kip}=4.49 \mathrm{kN}, 1 \mathrm{in}=25.4 \mathrm{~mm}$, $\left.1 \mathrm{ft} / \mathrm{sec}^{2}=0.31 \mathrm{~m} / \mathrm{sec}^{2}\right)$

\begin{tabular}{c|c|c|c}
\hline $\begin{array}{c}\text { Blast } \\
\text { Weight } \\
\text { (Kips) }\end{array}$ & Structure & $\begin{array}{c}\text { Roof } \\
\text { Deflection } \\
\text { (in) }\end{array}$ & $\begin{array}{c}\text { Roof } \\
\text { Acceleration } \\
\left(\mathrm{ft} / \mathrm{sec}^{2}\right)\end{array}$ \\
\hline \multirow{4}{*}{2} & MRF & 1.68 & 85 \\
\cline { 2 - 4 } & CBF & 1.33 & 41 \\
\cline { 2 - 4 } & EBF & 1.49 & 50 \\
\hline \multirow{4}{*}{4} & MRF & 2.3 & 89 \\
\cline { 2 - 4 } & CBF & 1.7 & 60 \\
\cline { 2 - 4 } & EBF & 2.2 & 63 \\
\hline
\end{tabular}

\section{Comparison of the seismic resisting framing systems}

The results of the plastic hinge analysis for both $2-\mathrm{K}$ $(8.9 \mathrm{kN})$ and $4-\mathrm{K}(17.8 \mathrm{kN})$ blasts show that the CBF developed the fewest number of plastic hinges, followed by the EBF and the MRF. The three framing systems also suffered similar loss of members: six members failed in the MRF, six members failed in the CBF and five members failed in the EBF for the 2-K $(8.9 \mathrm{kN})$ blast load and nine members in the MRF, eight members in the CBF and seven members in the EBF for the 4-K $(17.8 \mathrm{kN})$ blast load. The members failed almost immediately after detonation and all experienced similar initial blast forces.

Figures 12 and 13 present the roof deflection and acceleration in the direction of the blast for the MRF, $\mathrm{CBF}$, and EBF subjected to a blast load of 2-K $(8.9 \mathrm{kN})$, respectively. Figures 14 and 15 present the roof deflection and acceleration in the direction of the blast for the three structures subjected to a blast load of $4-\mathrm{K}(17.8 \mathrm{kN})$, respectively. Table 7 provides the maximum roof deflection and acceleration for the three structures for $2-\mathrm{K}(8.9 \mathrm{kN})$

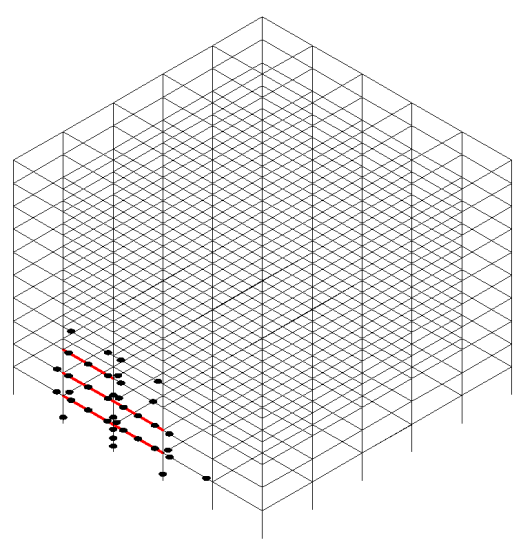

(a) MRF

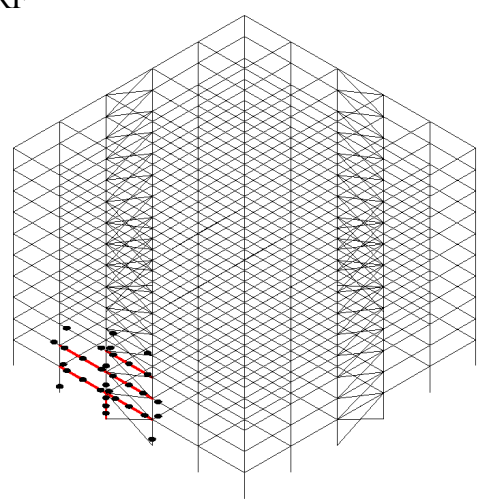

(b) $\mathrm{CBF}$

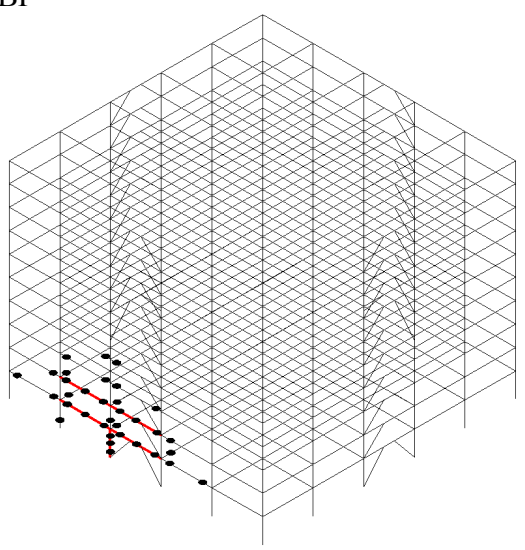

(c) $\mathrm{EBF}$

Fig. 10. Plastic hinge locations in MRF, CBF, EBF under a $2-\mathrm{K}(8.9 \mathrm{kN})$ blast (failed member are indicated by a thick line) 
and 4-K $(17.8 \mathrm{kN})$ blast loads. The CBF yielded the smallest roof acceleration and deflection, followed by the EBF and the MRF for both loading situations. Compared with the MRF, the CBF had $21 \%$ and $26 \%$ smaller maximum deflection and $52 \%$ and $33 \%$ smaller maximum acceleration for the 2-K $(8.9 \mathrm{kN})$ and $4-\mathrm{K}(17.8 \mathrm{kN})$ blast loads, respectively.

All three framing systems investigated in this research could not fully resist the effects of the initial blast forces and undergo damage and member failure. Overall, the braced frames appear to do a better job absorbing the blast forces resulting in fewer plastic hinge formations and yielding smaller roof deflection and acceleration.

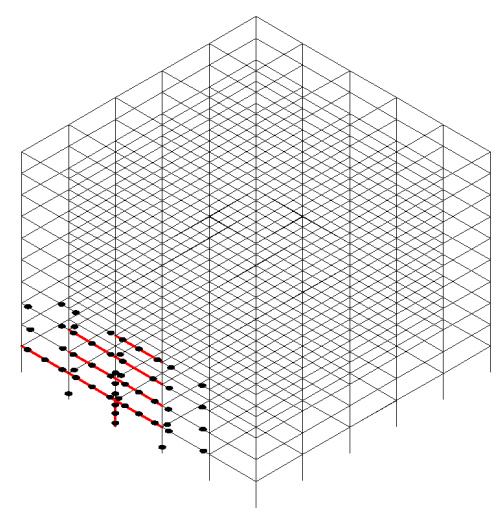

(a) MRF

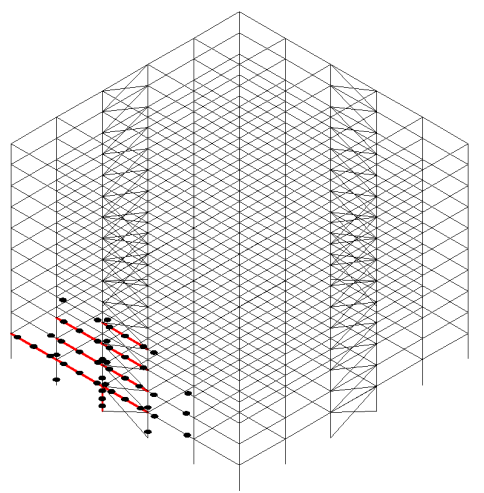

(b) $\mathrm{CBF}$

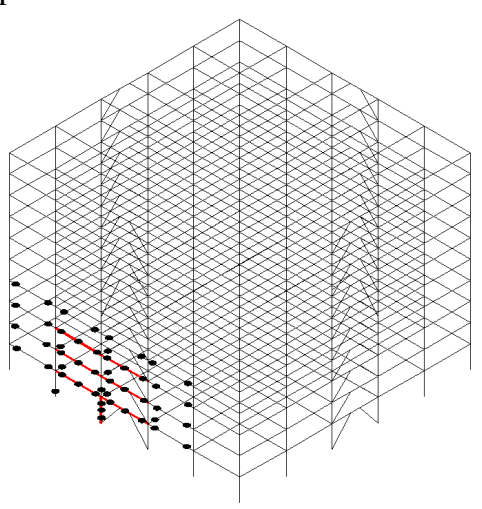

(c) EBF

Fig. 11. Plastic hinge locations in MRF, CBF, EBF under a 4-K2-K $(17.8 \mathrm{kN})$ blast (failed member are indicated by a thick line)

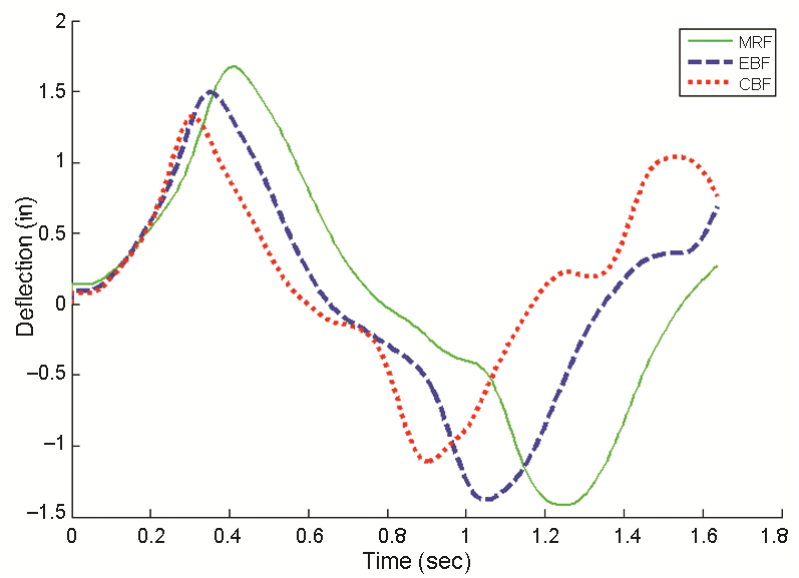

Fig. 12. Roof deflection under 2-K $(8.9 \mathrm{kN})$ blast $(1 \mathrm{in.}=25.4 \mathrm{~mm})$
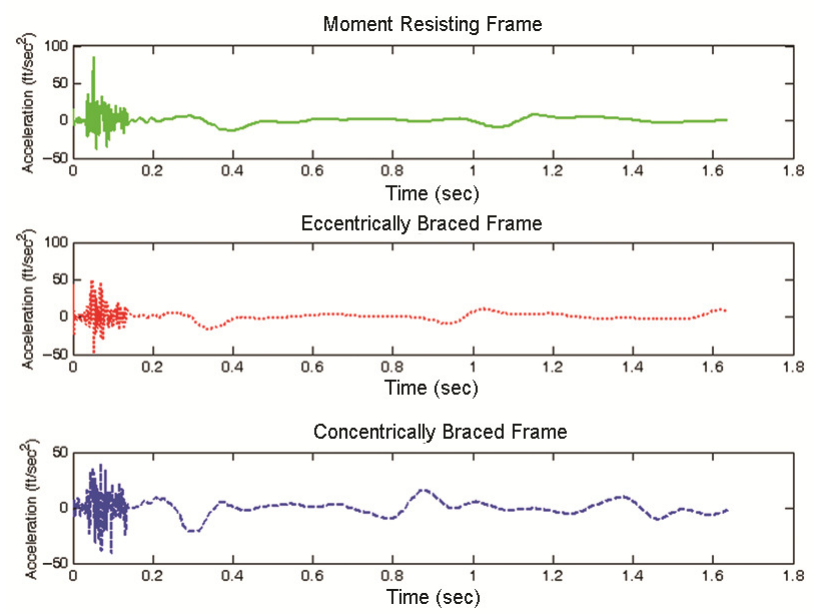

Fig. 13. Roof acceleration under 2-K $(8.9 \mathrm{kN})$ blast $\left(1 \mathrm{ft} / \mathrm{sec}^{2}=0.31 \mathrm{~m} / \mathrm{sec}^{2}\right)$

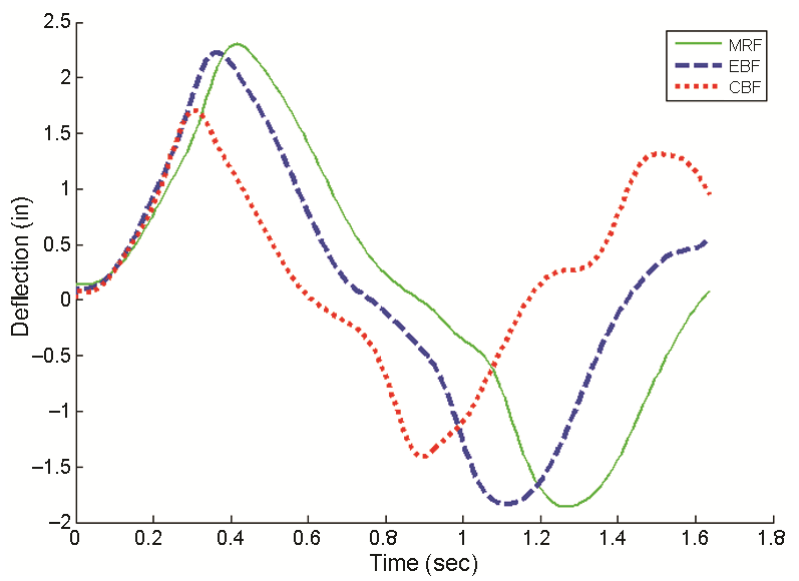

Fig. 14. Roof deflection under 4-K $(17.8 \mathrm{kN})$ blast $(1 \mathrm{in} .=25.4 \mathrm{~mm})$

\section{Conclusions}

The effectiveness of three commonly used seismically designed framing systems subjected to blast loading is investigated in this research. The main conclusion of this research is that braced frames provide a higher level of resistance to the blast loading scenario investigated in this 

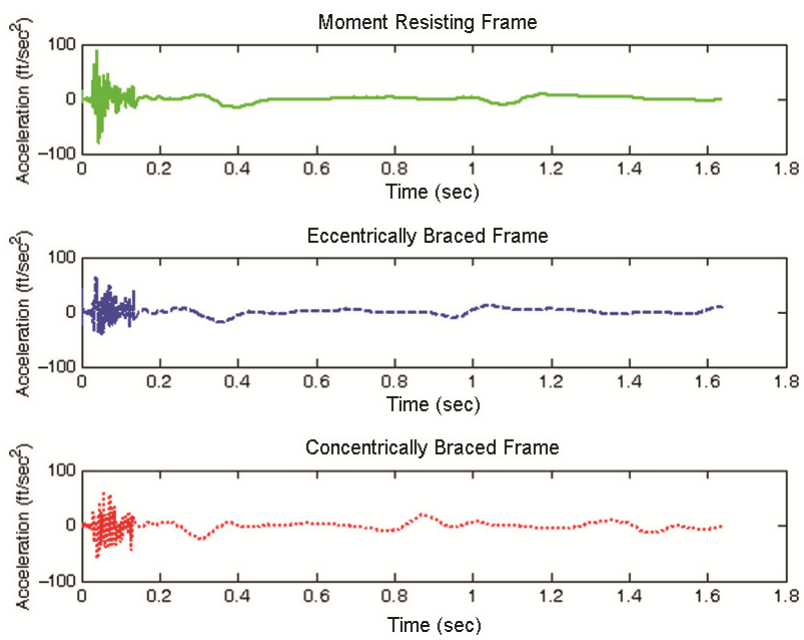

Fig. 15. Roof acceleration under $4-\mathrm{K}(17.8 \mathrm{kN})$ blast $\left(1 \mathrm{ft} / \mathrm{sec}^{2}=0.31 \mathrm{~m} / \mathrm{sec}^{2}\right)$

research. Both the CBF and EBF had a smaller number of failed members and plastic hinges compared to the MRF. They also produced a smaller roof deflection and acceleration. The CBF yielded the fewest number of plastic hinges and has the smallest maximum roof deflection and acceleration but the EBF had a slightly fewer number of failed members.

Blast analysis of a large 3D multistory structure is complicated and requires significant computing resources because a small time-step in the order of 0.0001 seconds must be used. As such in this research several simplifying assumptions were made on the application of the blast loads. Future research may include the negative and reflected pressures in the blast load profile. Strain rate effects on the material properties may be considered; especially if larger or closer range blast loads are used. More examples utilizing various stand-off distances and blast locations around the structure as well as application of other types of bracing systems can be subjects of future research. Structures of varying heights and configurations can also be investigated. There are other types of framing systems that are used in seismic regions that may be explored as well.

\section{Acknowledgements}

This research was performed using ELS (Extreme Loading for Structures) software system developed by Applied Science International, LLC (2010) that provides AEM capability. The assistance provided by Michael Hahn and Ayman El Fouly of ELS is gratefully acknowledged.

\section{References}

Adeli, H.; Chyou, H. 1986. Plastic analysis of irregular frames on microcomputers, Computers and Structures 23(2): 233-240.

http://dx.doi.org/10.1016/0045-7949(86)90215-4

Adeli, H.; Chyou, H. 1987. Microcomputer-aided optimal plastic design of frames, Journal of Computing in Civil Engineering ASCE 1(1): 20-34.

http://dx.doi.org/10.1061/(ASCE)0887-3801(1987)1:1(20)
Adeli, H.; Mabrouk, N. 1986. Optimum plastic design of unbraced frames of irregular configuration, International Journal of Solids and Structures 22(10): 1117-1128. http://dx.doi.org/10.1016/0020-7683(86)90021-1

Adeli, H.; Gere, J.; Weaver, Jr. W. 1978. Algorithms for nonlinear structural dynamics, Journal of the Structural Division ASCE 104(2): 263-280.

AISC. 2010. Steel construction manual. $14^{\text {th }}$ ed. American Institute of Steel Construction, Chicago. 2192 p.

Applied Science International, LLC. 2010. Extreme loading for structures modeling. Manual. Version 3.1.

ASCE. 2010. Minimum design loads for buildings and other structures - SEI/ASCE Standard No.7-10. American Society of Civil Engineers, Reston, VA. 658 p.

Ballantyne, G.; Whittaker, A.; Dargush, M.; Aref, A. 2010. Airblast effects on structural shapes of finite width, Journal of Structural Engineering 136(2): 152-159.

http://dx.doi.org/10.1061/(ASCE)ST.1943-541X.0000049

Finckh, W.; Zilch, K. 2012. Strengthening and rehabilitation of reinforced concrete slabs with carbon fiber reinforced polymers using a refined bond model, Computer-Aided Civil and Infrastructure Engineering 27(5): 333-346. http://dx.doi.org/10.1111/j.1467-8667.2011.00752.x

Friedlander, F. G. 1947. Simple progressive solutions of the wave equation, Mathematical Proceeding of the Cambridge Philosophical Society 43(3): 360-373. http://dx.doi.org/10.1017/S0305004100023598

Khandelwal, K.; E.-Tawil, S.; Sadek, F. 2009. Progressive collapse analysis of seismically designed steel braced frames, Journal of Constructional Steel Research 65: 699-708. http://dx.doi.org/10.1016/j.jcsr.2008.02.007

Kim, J.; Lee, Y.; Choi, H. 2011. Progressive collapse resisting capacity of braced frames, The Structural Design of Tall and Special Buildings 20: 257-270. http://dx.doi.org/10.1002/tal.574

Lee, K.; Kim, T.; Kim, J. 2009. Local response of W-shaped steel columns under blast loading, Structural Engineering and Mechanics 31(1): 25-38. http://dx.doi.org/10.12989/sem.2009.31.1.025

Lee, K.; Chung, L.; Lee, S.; Park, T.; Rho, J. 2011. Evaluation of dynamic collapse behavior of steel moment frames damaged by blast, Applied Mechanics and Materials 82: 402-409.

http://dx.doi.org/10.4028/www.scientific.net/AMM.82.404

Luccioni, B.; Ambrosini, R.; Danesi, R. 2004. Analysis of building collapse under blast loads, Engineering Structures 26(1): 63-71.

http://dx.doi.org/10.1016/j.engstruct.2003.08.011

Lupoae, M.; Bucur, C. 2009. Use of Applied Element Method to simulate the collapse of a building, in The Annual Symposium of the Institute of Solid Mechanics, 28-29 May 2009, Bucharest, Romania, 13-18.

Myorca, P.; Meguro, K. 2004. Proposal of an efficient technique for retrofitting unreinforced masonry dwelling, in The $13^{\text {th }}$ Annual Conference on Earthquake Engineering, 1-6 August 2004, Vancouver, B.C., Canada. Paper No. 2431.

Meguro, K.; Tegel-Din, H. 2000. Applied Element Method for structural analysis: theory and application for linear materials, Structural Engineering 17(1): 21-35.

Ngo, T.; Mendis, P.; Gupta, A.; Ramsay, J. 2007. Blast loading and blast effects on structures - an overview, Electronic Journal of Structural Engineering (Special Issue: Loading on Structures): 76-91. 
Park, H. S.; Adeli, H. 1995. A neural dynamics model for structural optimization - application to plastic design of structures, Computers \& Structures 57(3): 391-399. http://dx.doi.org/10.1016/0045-7949(95)00047-K

Saleh, A.; Adeli, H. 1998. Optimal control of adaptive building structures under blast loading, Mechatronics 8(8): 821844. http://dx.doi.org/10.1016/S0957-4158(98)00025-7

Sasani, M. 2008. Response of a reinforced concrete infilledframe structure to removal of two adjacent columns, Engineering Structures 30: 2478-2491. http://dx.doi.org/10.1016/j.engstruct.2008.01.019

UFC. 2008. Structures to resist the effects of accidental explosions. UFC-340-2. Department of Defense, Washington, D.C., USA. 12 p.
Young, K.; Adeli, A. 2013. Fundamental period of irregular moment resisting steel frames, The Structural Design of Tall and Special Buildings 23(15): 1141-1157. http://dx.doi.org/10.1002/tal.1112

Young, K.; Adeli, A. 2014. Fundamental period of irregular concentrically braced steel frame structures, The Structural Design of Tall and Special Buildings 23(16): 12111224. http://dx.doi.org/10.1002/tal.1136

Yusof, M. A.; Norazman; Ariffin; Zain, F.; Risby; Ng, C. P. 2010. Normal strength steel fiber reinforced concrete subjected to explosive loading, International Journal of Sustainable Construction Engineering \& Technology 1(2): $127-136$

Amy COFFIELD. She graduated from The Ohio State University in 2010 with a Bachelor's of Science Degree in Civil Engineering. She received her Master's of Science Degree in Civil Engineering from The Ohio State University in 2013. Since 2012 she has worked as a Structural Engineer at River Consulting in Columbus, Ohio.

Hojjat ADELI. He is Professor of Civil, Environmental, and Geodetic Engineering, Biomedical Engineering, Biomedical Informatics, Electrical and Computer Engineering, Neurological Surgery, and Neuroscience at The Ohio State University. He has authored of over 500 publications including 15 books since he received his PhD. from Stanford University in 1976 at the age of 26 . He is the recipient of numerous awards and honors including The Ohio State University's highest research honor, the Distinguished Scholar Award "in recognition of extraordinary accomplishment in research and scholarship". He is the quadruple-winner of the OSU College of Engineering Lumley Outstanding Research Award. He received the ASCE Construction Management Award in 2006. In 2007 he received the Peter L. and Clara M. Scott Award for Excellence in Engineering Education for sustained, exceptional, and multi-faceted contributions to numerous fields including computer-aided engineering, knowledge engineering, computational intelligence, large-scale design optimization, and smart structures with worldwide impact, and Charles E. MacQuigg Outstanding Teaching Award from The Ohio State University College of Engineering. He is also the 2014 recipient of Eduardo Renato Caianiello Award from the Italian Society of Neural Networks (SIREN), and a Special Medal from the Polish Neural Network Society. In 1998 he was awarded a United States patent for his neural dynamics model for design automation and optimization (jointly with a former $\mathrm{PhD}$ student). He is a Fellow of AAAS, IEEE, and the American Neurological Association, and is the Editor-in-Chief of the international research journals Computer-Aided Civil and Infrastructure Engineering which he founded in 1986 and Integrated Computer-Aided Engineering which he founded in 1993, and the International Journal of Neural Systems. 